\title{
CAPÍTULO 05: FORMULAÇÕES DE GELEIAS DE RAPADURA E MELADO DE CANA-DE-AÇÚCAR: CARACTERIZAÇÃO FÍSICO-QUÍMICA E SENSORIAL
}

\section{CHAPTER 05: FORMULATIONS OF RAPADURA JAMES AND SUGAR CANE HONEY: PHYSICAL-CHEMICAL AND SENSORIAL CHARACTERIZATION}

\author{
Erika de Sousa Dias ${ }^{1}$; Emanuel Neto Alves de Oliveira ${ }^{2}$; Wisla Kívia de Araújo Soares ${ }^{3}$; Bruno \\ Fonsêca Feitosa ${ }^{4}$; Edilayane da Nóbrega Santos ${ }^{5}$
}

\begin{abstract}
Resumo
O beneficiamento da cana-de-açúcar através dos seus derivados possui alta aceitabilidade comercial, podendo serem utilizados na elaboração de novos produtos com apelo regional. Assim, objetivou-se desenvolver formulações de geleias de rapadura e melado de cana-deaçúcar, bem como analisar as características físico-químicas e sensoriais. As geleias foram desenvolvidas através de testes preliminares, sendo avaliados os parâmetros físico-químicos, aceitação sensorial de atributos, Índice de Aceitabilidade e intenção de compra. Os resultados foram analisados através de Análise de Variância, em Delineamento Inteiramente Casualizado, sendo as médias comparadas pelo teste de Tukey, a nível de 5\% de significância. O teor de água da geleia de rapadura $(30,49 \%)$ foi inferior ao da geleia de melado $(38,61 \%)$. A geleia de melado foi caracterizada com pH ácido $(3,51)$ e maior sensação de doçura. Ambos os produtos estão menos susceptíveis a multiplicação de microrganismos, devido aos baixos valores de atividade de água. Houveram diferenças significativas entre as geleias nos atributos sensoriais aparência, consistência, espalhabilidade e impressão global. Infere-se que as formulações foram validadas, evidenciando produtos inovadores e com expressivo apelo regional. Ambas as formulações foram bem aceitas sensorialmente, com índice de aceitabilidade acima de $70 \%$ em todos os atributos, destacando-se a geleia de melado de cana-de-açúcar.
\end{abstract}

Palavras-Chaves: Aceitabilidade, Novos produtos, Saccharum officinarum.

\begin{abstract}
\footnotetext{
1 Técnica em Alimentos, IFRN, erika_souza9@ hotmail.com

${ }^{2}$ Docente da área de Tecnologia de Alimentos, IFRN, emanuel.oliveira16@gmail.com

${ }^{3}$ Engenharia de Alimentos, CCTA/UFCG, wisla-kivia@ hotmail.com

${ }^{4}$ Engenharia de Alimentos, CCTA/UFCG, brunofonsecafeitosa@live.com

${ }^{5}$ Engenharia de Alimentos, CCTA/UFCG, layane.nobrega@hotmail.com
}

The processing of sugarcane through its derivatives has a high commercial acceptability and can be used in the development of new products with regional appeal. Thus, the objective was to develop formulations of rapadura jellies and sugarcane molasses, as well as to analyze the physical-chemical and sensory characteristics. The jellies were developed through preliminary tests, being evaluated the physical-chemical parameters, sensory acceptance of attributes, Acceptability Index and purchase intention. The results were analyzed using Analysis of Variance, in a Completely Randomized Design, and the means were compared by the Tukey test, at the level of $5 \%$ of significance. The water content of rapadura jelly (30.49\%) was lower than that of molasses jelly (38.61\%). The molasses jelly was characterized with an acidic $\mathrm{pH}$ (3.51) and a greater sensation of sweetness. Both products are less susceptible to the multiplication of microorganisms, due to the low values of water activity. There were significant differences between the jellies in the sensory attributes of appearance, consistency, spreadability and overall impression. It is inferred that the formulations were validated, showing innovative products and expressive regional appeal. Both formulations were well accepted sensorially, with an acceptability index above $70 \%$ in all attributes, especially sugar cane 
DIAS, E. S. et al.

molasses jelly.

Keywords: Acceptability, New products, Saccharum officinarum.

\section{Introdução}

A produção de cana-de-açúcar (Saccharum officinarum) no Brasil iniciou a partir do período colonial, sendo trazida pelos colonizadores, que impulsionaram a formação dos primeiros engenhos no país. O clima ofereceu condições favoráveis para o desenvolvimento da planta, além de terem sido comercializadas as primeiras mudas (DELGADO et al., 2016; SANTOS; BORÉM, 2016). Na safra de 2018/19, a produção de cana-de-açúcar no Brasil atingiu 620,44 milhões de toneladas (CONAB, 2019), destacando-se a importância para o agronegócio, principalmente, na região Nordeste (DÍAZ; QUINONEZ, 2017).

Através do beneficiamento da cana-de-açúcar, obtém-se o melado e a rapadura, que são produtos com alta aceitabilidade comercial e de fácil produção (SEBRAE, 2014). Comumente, tornaram-se fontes de geração de renda e empregos para o homem do campo, sendo fabricados artesanalmente em engenhos (DELGADO et al., 2016), com matéria-prima não fermentada, isenta de matéria terrosa, parasitos, detritos animais e vegetais. Esses produtos devem ser isentos de qualquer adição de essências, corantes naturais ou artificiais, conservadores e edulcorantes (BRASIL, 1978).

A rapadura é obtida a partir da concentração do caldo-de-cana quente, caracterizada por ser de massa dura, cor âmbar castanha, aroma e sabor específicos (AZEVÊDO et al., 2015; DÍAZ; QUINONEZ, 2017; JERONIMO, 2018). O fácil acesso e alto valor nutricional da rapadura elevam o consumo majoritariamente no sertão nordestino (BATISTA et al, 2019), posto que o desenvolvimento de novas apresentações é uma estratégia para promover esse consumo (AZEVÊDO et al. 2015). De acordo com a Tabela Brasileira de Composição de Alimentos (TACO), para cada $100 \mathrm{~g}$ de rapadura há $368 \mathrm{Kcal}$ de valor energético, 0,67 g de proteínas, $90 \mathrm{~g}$ de carboidratos, 0,63 g de lipídeos e não apresenta fibra alimentar e colesterol (TACO, 2020).

O melado é obtido a partir do caldo-de-cana ou até mesmo da rapadura, através de processos tecnológicos, que diferem pelo tempo de cozimento. Trata-se do primeiro produto a ser formado, passando aproximadamente 3 horas sob aquecimento (RADDATTZ et al, 2015). De acordo com a TACO, para cada $100 \mathrm{~g}$ de rapadura há $306 \mathrm{Kcal}$ de valor energético, 76,6 g de carboidratos e não apresenta proteínas, lipídeos, fibra alimentar e colesterol (TACO, 2020). Assim como os demais derivados da cana-de-açúcar, a rapadura e o melado são comumente 
utilizados como adoçante, consumidos in natura (VICENTINI-POLETTE, 2019) ou podem ser submetidos a processos tecnológicos para a produção de doces e geleias.

A Agência Nacional de Vigilância Sanitária (ANVISA) define geleia de fruta como "o produto obtido pela cocção, de frutas, inteiras ou em pedaços, polpa ou suco de frutas, com açúcar e água e concentrado até consistência gelatinosa" (BRASIL, 1978; 2005). Tendo em vista a elaboração de novos produtos com o apelo regional, objetivou-se com esta pesquisa desenvolver formulações de geleias de rapadura e melado de cana-de-açúcar, bem como analisar as características físico-químicas e sensoriais.

\section{Material e Métodos}

A pesquisa foi desenvolvida no Instituto Federal de Educação, Ciência e Tecnologia do Rio Grande do Norte, campus Pau dos Ferros, localizado no Alto Oeste Potiguar, Rio Grande do Norte, Brasil. As matérias-primas foram adquiridas no comércio local da cidade de Pau dos Ferros-RN.

Através de testes preliminares, as geleias foram elaboradas no Laboratório da Unidade Industrial Escola do referido campus, conforme as formulações apresentadas na Tabela 1.

Tabela 1. Formulações das geleias de rapadura e melado de cana-de-açúcar

\begin{tabular}{ccccc}
\hline & \multicolumn{4}{c}{ Formulações } \\
\cline { 2 - 5 } Ingredientes & \multicolumn{2}{c}{ Geleia de rapadura } & \multicolumn{2}{c}{ Geleia de melado } \\
\cline { 2 - 5 } & $\mathrm{g}$ & 30,5 & $\mathrm{~g}$ & $\%$ \\
\hline Rapadura & 2500 & - & 2500 & 30,5 \\
Melado & - & 48,8 & 4000 & 48,8 \\
Água & 4000 & 12,2 & 1000 & 12,2 \\
Sacarose & 1000 & 8,5 & 70 & 8,5 \\
\hline Pectina de ATM* & 70 & & & - \\
\hline
\end{tabular}

*ATM - Alto Teor de Metoxilação.

Fonte: Própria (2020).

Inicialmente, a rapadura foi submetida ao processo de raspagem com facas de aço inoxidável para facilitar a posterior homogeneização com os demais ingredientes. A pectina de Alto Teor de Metoxilação (ATM) e a sacarose foram misturados em panela de aço inoxidável e, respectivamente para cada formulação, acrescentou-se a rapadura ou o melado de cana-deaçúcar e os demais ingredientes manualmente.

As misturas foram submetidas ao aquecimento até atingirem teores de sólidos solúveis totais mínimos de $65^{\circ}$ Brix para a geleia de rapadura e de $55^{\circ}$ Brix para a geleia de melado de cana-de-açúcar. Então, o aquecimento foi interrompido e as geleias, ainda quentes, foram envasadas em potes de vidro de $200 \mathrm{~mL}$ com tampas metálicas, sendo posteriormente invertidos 
por 5 segundos, a fim de promover o tratamento térmico da tampa e evitar o desenvolvimento de microrganismos. Em seguida, as geleias foram resfriadas, através de imersão em água a temperatura ambiente, e armazenadas em prateleiras nessa mesma condição de temperatura.

As análises físico-químicas foram realizadas no Laboratório de Análise Físico-Química de Alimentos do referido campus. As geleias foram analisadas, em triplicata, quanto aos parâmetros:

- Teor de água (\%) e sólidos totais (\%): Secagem em estufa, a $105^{\circ} \mathrm{C} / 24 \mathrm{~h}$, segundo normas do Instituto Adolfo Lutz (IAL, 2008);

- Cinzas (\%): Incineração em forno mufla, a $550^{\circ} \mathrm{C} / 6 \mathrm{~h}$, segundo normas do Instituto Adolfo Lutz (IAL, 2008);

- $\quad$ pH: Método potenciométrico, através de pHmetro digital, calibrado com soluções tampão pH 4,0 e 7,0, segundo normas do Instituto Adolfo Lutz (IAL, 2008);

- Acidez total titulável (\%): Método titulometria, com neutralização dos ácidos, utilizando solução de Hidróxido de Sódio $(\mathrm{NaOH})$ a $0,1 \mathrm{~N}$ e indicador fenolftaleína a $1 \%$, segundo normas do Instituto Adolfo Lutz (IAL, 2008);

- Sólidos solúveis totais ( ${ }^{\circ}$ Brix): Determinada em refratômetro manual, segundo normas do Instituto Adolfo Lutz (IAL, 2008);

- Ratio: Calculado pela razão entre os sólidos solúveis totais e acidez total titulável;

- Açúcares totais e redutores (\%): Método de Lane-Eynon com solução de Fehling A e B, segundo normas do Instituto Adolfo Lutz (IAL, 2008);

- Açúcares não redutores (\%): Foi determinado pela diferença entre os açúcares totais e redutores, segundo normas do Instituto Adolfo Lutz (IAL, 2008);

- Atividade de água: Determinada em equipamento digital de bancada, segundo normas do Instituto Adolfo Lutz (IAL, 2008);

As análises sensoriais foram realizadas no Laboratório de Análise Sensorial de Alimentos do referido campus. Procedeu-se com 56 provadores não treinados, sendo aplicado teste de aceitação com base na metodologia descrita por Dutcosky (2013). Os provadores receberam uma amostra de cada formulação, um copo com água para a limpeza do palato e bolacha tipo água e sal para testar a espalhabilidade das geleias.

Para o teste de aceitação sensorial dos atributos cor, aparência, aroma, sabor, doçura, consistência, espalhabilidade e impressão global foi utilizada uma escala hedônica estruturada de 9 pontos: 1 - desgostei muitíssimo, 2 - desgostei muito, 3 - desgostei moderadamente, 4 desgostei ligeiramente, 5 - não gostei/ nem desgostei, 6 - gostei ligeiramente, 7 - gostei moderadamente, 8 - gostei muito e 9 - gostei muitíssimo (DUTCOSKY, 2013). 
Com os dados obtidos dos atributos sensoriais foi calculado o Índice de Aceitabilidade para cada atributo (Equação 1), de acordo com Gularte (2009).

$$
I A(\%)=\frac{M}{N} * 100
$$

Em que:

M - média do somatório dos resultados dos provadores;

$\mathrm{N}$ - número de pontos utilizados na escala de avaliação.

Também avaliada a intenção de compra das geleias, utilizando uma escala estruturada de 5 pontos: 1 - certamente não compraria, 2 - possivelmente não compraria, 3 - talvez compraria/ talvez não compraria, 4 - possivelmente compraria e 5 - certamente compraria (DUTCOSKY, 2013).

A pesquisa foi realizada em Delineamento Inteiramente Casualizado (DIC). Os resultados obtidos foram analisados com o auxílio do software Assistat versão 7.7 beta (SILVA; AZEVEDO, 2016), através de Análise de Variância (ANOVA). As médias foram comparadas pelo teste de Tukey, a nível de 5\% de significância $(\mathrm{p}<0,05)$.

\section{Resultados e Discussão}

$\mathrm{Na}$ Tabela 2 estão apresentados os resultados obtidos nas análises físico-químicas das geleias de rapadura e melado de cana-de-açúcar. Houveram diferenças significativas $(\mathrm{p}<0,05)$ entre as geleias para todos os parâmetros físico-químicos analisados.

Tabela 2. Resultados das análises físico-químicas das geleias de rapadura e melado de cana-de-açúcar

\begin{tabular}{ccc}
\hline Parâmetros & \multicolumn{2}{c}{ Formulações } \\
\cline { 2 - 3 } & Geleia de rapadura & Geleia de melado \\
\hline Teor de água (\%) & $30,49^{\mathrm{b}} \pm 0,15$ & $38,61^{\mathrm{a}} \pm 0,27$ \\
Sólidos totais (\%) & $69,51^{\mathrm{a}} \pm 0,15$ & $61,39^{\mathrm{b}} \pm 0,27$ \\
Cinzas (\%) & $0,77^{\mathrm{a}} \pm 0,03$ & $0,16^{\mathrm{b}} \pm 0,02$ \\
pH & $5,56^{\mathrm{a}} \pm 0,05$ & $3,51^{\mathrm{b}} \pm 0,12$ \\
Acidez total titulável $(\%)$ & $0,24^{\mathrm{a}} \pm 0,02$ & $0,16^{\mathrm{b}} \pm 0,02$ \\
Sólidos solúveis totais ( ${ }^{\circ}$ Brix) & $67,00^{\mathrm{a}} \pm 0,00$ & $58,00^{\mathrm{b}} \pm 0,00$ \\
Ratio & $246,73^{\mathrm{b}} \pm 17,05$ & $417,87^{\mathrm{a}} \pm 15,11$ \\
Açúcares totais $(\%)$ & $92,79^{\mathrm{a}} \pm 1,40$ & $87,08^{\mathrm{b}} \pm 1,25$ \\
Açúcares redutores $(\%)$ & $12,51^{\mathrm{b}} \pm 0,40$ & $63,23^{\mathrm{a}} \pm 0,24$ \\
Açúcares não redutores $(\%)$ & $76,26^{\mathrm{a}} \pm 1,23$ & $22,66^{\mathrm{b}} \pm 0,70$ \\
Atividade de água & $0,77^{\mathrm{b}} \pm 0,00$ & $0,82^{\mathrm{a}} \pm 0,00$
\end{tabular}

Médias seguidas na linha pela mesma letra não diferem significativamente entre si pelo teste de Tukey a 5\% de significância.

Fonte: Própria (2020). 
O teor de água da geleia de rapadura $(30,49 \%)$ foi inferior ao da geleia de melado $(38,61 \%)$, possivelmente devido a rapadura ser um alimento sólido e seco, com menos umidade em sua composição. Também observou-se na geleia de rapadura um maior teor de sólidos totais e cinzas.

Semelhante aos resultados desta pesquisa, Garcia et al. (2017) obtiveram teor de água de $35,31 \%$, ao avaliarem a geleia de buriti. Oliveira et al. (2018) obtiveram uma variação de 38,43 a $42,42 \%$ de teor de umidade, ao avaliarem as amostras convencionais de geleias de umbu-cajá.

Maia et al. (2014) obtiveram teor de cinzas de 0,36\%, ao avaliarem a geleia de tamarindo, estando inferior ao teor da geleia de rapadura e superior ao teor da geleia de melado, porque a rapadura é concentrada durante o processamento, tornando-se mais seca e com maior teor de sólidos.

Quanto ao parâmetro $\mathrm{pH}$, a geleia de melado apresentou o menor valor médio de 3,51, caracterizado com pH ácido, quando comparado com a geleia de rapadura $(5,56)$. A geleia de melado também apresentou valor de acidez total titulável inferior em relação a geleia de rapadura.

Observou-se que o resultados obtidos para a geleia de melado aproximou-se ao valor encontrado por Caetano et al. (2012), na produção de geleia de acerola a partir da polpa, com pH 3,48. Gomes et al. (2013), na produção de geleia de maracujá e cenoura, obtiveram um valor de acidez total titulável de $0,77 \%$, provavelmente devido a composição química do maracujá.

O teores de sólidos solúveis totais obtidos para os produtos foram de $67^{\circ}$ Brix (geleia de rapadura) e $58^{\circ}$ Brix (geleia de melado). Vale ressaltar que a legislação preconiza o mínimo de 62 e $65^{\circ}$ Brix para a geleia comum e extra, respectivamente, quando a geleia são elaboradas com vegetais (BRASIL, 1978; 2005). Oliveira et al. (2019), ao elaborarem geleias de achachairu adoçadas com açúcar cristal e mascavo, obtiveram os teores de 65,71 e $67,40{ }^{\circ}$ Brix, respectivamente.

A geleia de melado apresentou um valor médio de Ratio de 417,87, indicando o produto com maior sensação de doçura. Segundo Castro et al. (2015), a relação entre sólidos solúveis totais e acidez total titulável está relacionada a doçura. Oliveira et al. (2016), ao elaborarem e avaliarem a geleia de laranja e de laranja com hortelã, obtiveram média geral de Ratio de 157,73 .

A geleia de rapadura apresentou uma média para o teor de açúcares totais e não redutores de 92,79 e 76,26\%, respectivamente, estando superiores aos teores da geleia de melado. 
Segundo Azevêdo et al. (2015), a composição da rapadura possui predominantemente sacarose, um tipo de açúcar não redutor.

No entanto, no que diz respeito aos teores de açúcares redutores, observou-se resultados maiores na geleia de melado (63,23\%). É possível justificar esse fato, segundo Emídio (2016), devido ao melado de cana-de-açúcar apresentar na sua composição um valor igual ou superior a $30 \%$ de glicose, visando impedir a recristalização da sacarose.

A geleia de melado apresentou um maior valor de atividade de água em relação a geleia de rapadura. Porém, ambos os produtos estão menos susceptíveis a multiplicação de microrganismos, devido aos baixos valores de atividade de água obtidos. Conforme Barros et al. (2019), a atividade de água é proporcional a susceptibilidade do desenvolvimento de microrganismos. Teles et al. (2017) desenvolveram uma geleia comum de graviola com pimenta, utilizando $0,5 \%$ de pectina, e obtiveram o valor de 0,81 , estando semelhante a geleia de melado da presente pesquisa.

Na Tabela 3 e Figura 1 estão apresentados, respectivamente, os resultados obtidos nas análises de aceitação sensorial e Índice de Aceitabilidade (IA) para cada atributo das geleias de rapadura e melado de cana-de-açúcar. Houveram diferenças significativas $(p<0,05)$ entre as geleias nos atributos sensoriais de aparência, consistência, espalhabilidade e impressão global.

Tabela 3. Resultados das análises sensoriais das geleias de rapadura e melado de cana-de-açúcar

\begin{tabular}{ccc}
\hline Atributos & \multicolumn{3}{c}{ Formulações } \\
\cline { 2 - 3 } & Geleia de rapadura & Geleia de melado \\
\hline Cor & $7,98^{\mathrm{a}} \pm 0,84$ & $8,27^{\mathrm{a}} \pm 0,84$ \\
Aparência & $7,75^{\mathrm{b}} \pm 0,92$ & $8,21^{\mathrm{a}} \pm 0,97$ \\
Aroma & $7,38^{\mathrm{a}} \pm 1,33$ & $7,77^{\mathrm{a}} \pm 1,22$ \\
Sabor & $7,75^{\mathrm{a}} \pm 1,28$ & $7,88^{\mathrm{a}} \pm 1,25$ \\
Doçura & $7,61^{\mathrm{a}} \pm 1,15$ & $7,71^{\mathrm{a}} \pm 1,22$ \\
Consistência & $6,91^{\mathrm{b}} \pm 1,12$ & $7,88^{\mathrm{a}} \pm 1,10$ \\
Espalhabilidade & $7,39^{\mathrm{b}} \pm 1,33$ & $7,93^{\mathrm{a}} \pm 1,22$ \\
Impressão Global & $7,68^{\mathrm{b}} \pm 1,18$ & $8,07^{\mathrm{a}} \pm 0,99$ \\
\hline
\end{tabular}

Médias seguidas na linha pela mesma letra não diferem significativamente entre si pelo teste de Tukey a 5\% de significância.

Fonte: Própria (2020).

$\mathrm{O}$ atributo cor não apresentou diferença significativa entre as geleias $(\mathrm{p}<0,05)$, com notas médias que variaram entre os termos hedônicos "gostei moderadamente" e "gostei muitíssimo". Os IA obtidos foram de 88,69 e 91,87\% para as geleias de rapadura e melado, respectivamente. Oliveira et al. (2015), ao analisarem sensorialmente as geleias convencionais de umbu-cajá, obtiveram nota média de 7,53, que foram menores do que as notas obtidas pelas geleias do presente estudo. 
Figura 1. Índices de Aceitabilidade (IA) das geleias de rapadura e melado de cana-de-açúcar.

Cor

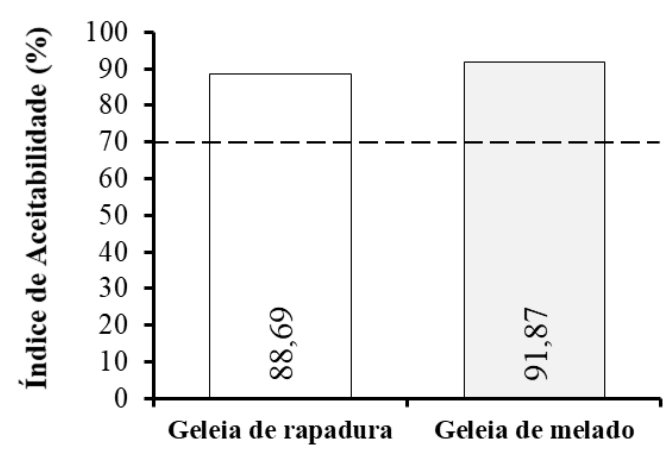

Aroma

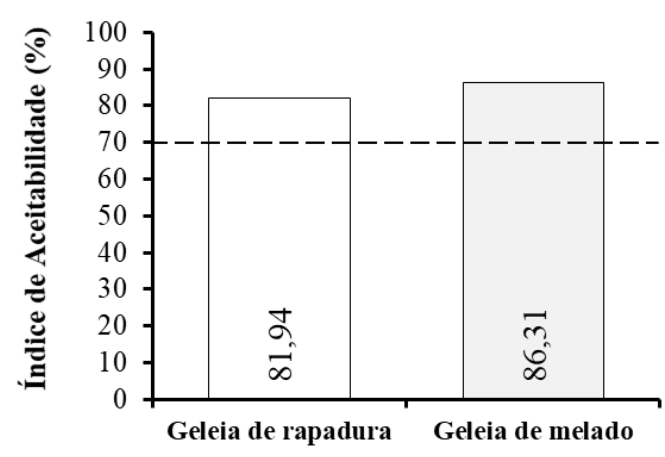

Doçura
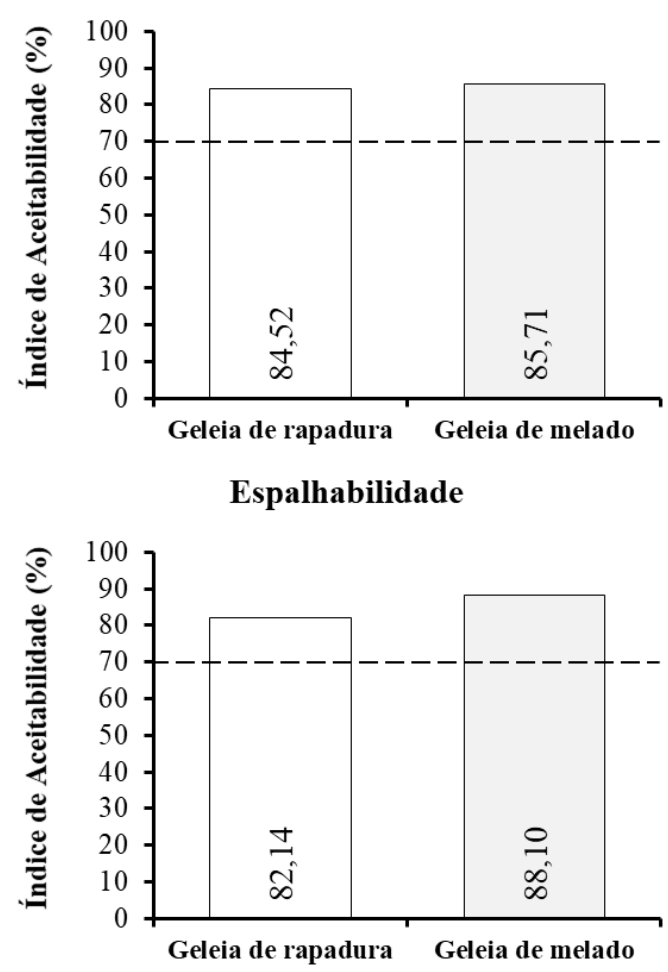

Aparência

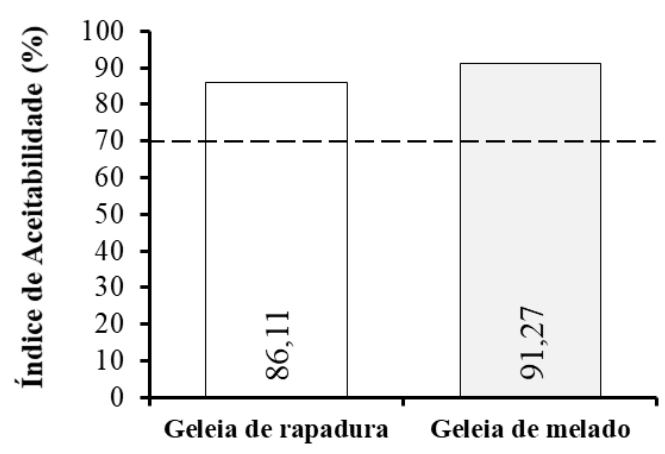

Sabor

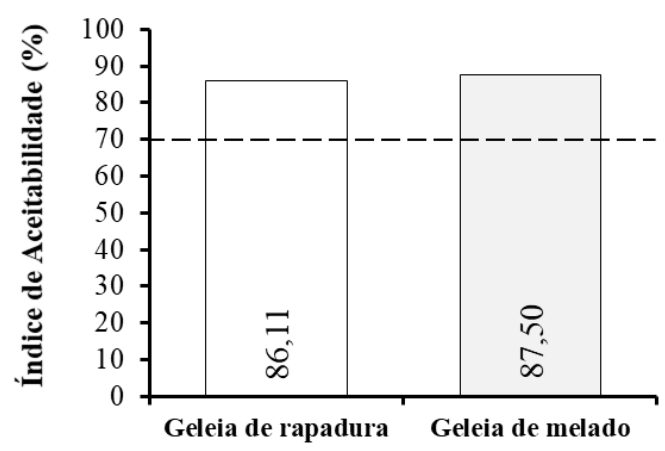

Consistência
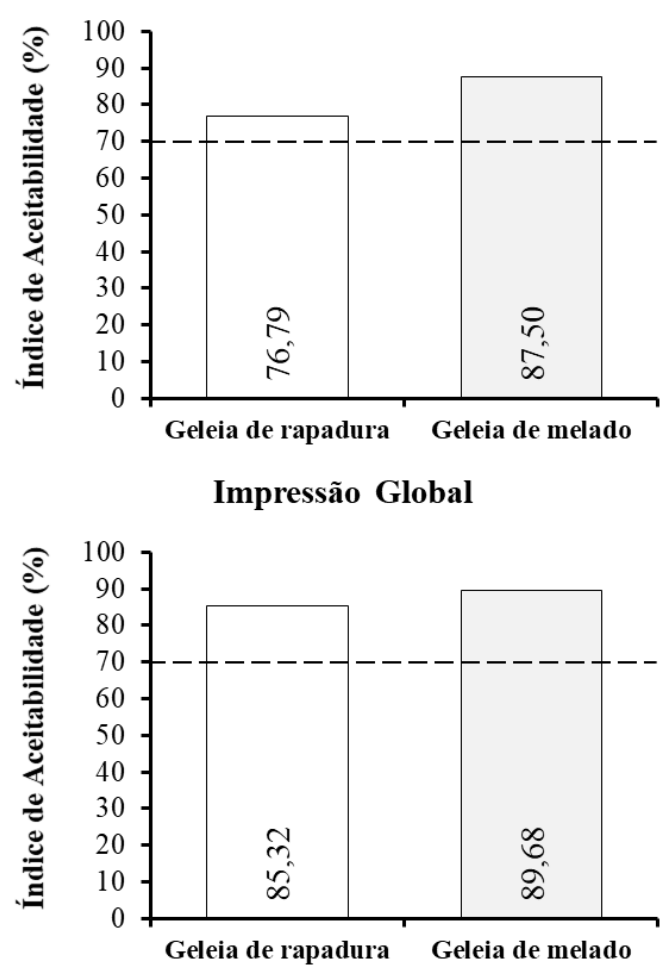

Fonte: Própria (2020). 
Nos atributos aparência e impressão global as notas foram superiores para a geleia de melado, posto que variaram entre os termos hedônicos "gostei moderadamente" e "gostei muitíssimo". Os IA obtidos foram de 91,27\% para aparência e 89,68\% para impressão global, ambos da geleia de melado. Rybka et al. (2018), ao analisarem a geleia de manga adicionada de fibras, obtiveram IA médio de 77,17\% para a impressão global, estando menor do que os resultados das geleias na presente pesquisa.

As geleias no atributo aroma não apresentaram diferenças significativas entre si $(\mathrm{p}<0,05)$, com notas médias que variaram entre os termos hedônicos "gostei moderadamente" e "gostei muito". Os IA obtidos foram de 81,94 e 86,31\% para as geleias de rapadura e melado, respectivamente.

Os atributos sabor e doçura não apresentaram diferenças significativas entre as geleias $(\mathrm{p}<0,05)$, com notas médias que variaram entre os termos hedônicos "gostei moderadamente" e "gostei muito". Os IA variaram entre 84,52 e 87,50\% nas geleias de rapadura e melado, respectivamente. Nesses atributos as matérias-primas utilizadas nas formulações das geleias não interferiram na aceitação sensorial pelos provadores. Vieira et al. (2017), ao avaliarem a geleia mista de casca de abacaxi e polpa de pêssego, obtiveram média de 8,40 no atributo sabor.

O atributo consistência está fortemente ligado ao teor de sólidos solúveis totais (BARRETO et al., 2015). Quanto aos atributos consistência e espalhabilidade, não houveram diferença significativas entre as geleias $(\mathrm{p}<0,05)$. As notas médias variaram entre os termos hedônicos "gostei ligeiramente" e "gostei muito". Os IA variaram entre 76,79 e 88,10\% nas geleias de rapadura e melado.

Souza et al. (2016) produziram geleias de tamarindo com pectina e obtiveram notas médias entre 8,00 e 8,28 para a consistência. As geleias da presente pesquisa foram elaboradas a partir de derivados do caldo de cana-de-açúcar, que conservam todos os nutrientes presentes nessa matéria-prima (SOARES, 2017), mas que não contém quantidade substancial de pectina. Guilherme et al. (2012), ao analisarem geleia de tamarillo, obtiveram nota média de 6,6 para o atributo espalhabilidade.

Na Figura 2 estão apresentados os resultados do Índice de Aceitabilidade Geral das geleias de rapadura e melado de cana-de-açúcar.

Verifica-se que a Aceitabilidade Geral das geleias desenvolvidas na presente pesquisa foram superiores a 70\%. Segundo Gularte (2009), um produto deve apresentar o percentual mínimo de $70 \%$ no IA para ser cogitado ao lançamento no mercado. Os valores demostraram boa aceitabilidade sensorial das geleias, independente da matéria-prima usada. 
Figura 2. Aceitabilidade Geral das geleias de rapadura e melado de cana-de-açúcar.

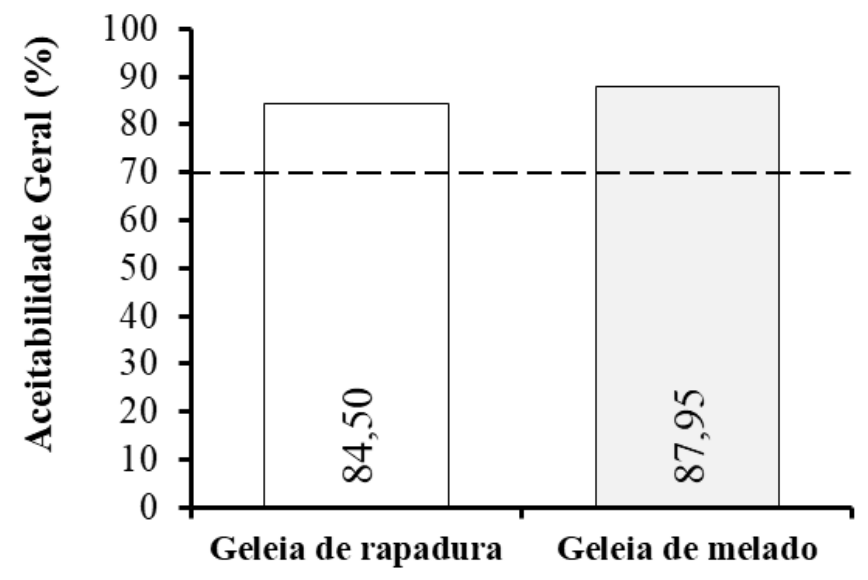

Fonte: Própria (2020).

Porém, a geleia de melado apresentou um resultado superior, com 87,95\%. Oliveira Neto et al. (2016), ao elaborarem e avaliarem geleias enriquecidas com farinha do resíduo agroindustrial de abacaxi, obtiveram uma variação na Aceitabilidade Geral entre 69,83 e $77,18 \%$, estando menores aos resultados obtidos na presente pesquisa.

Na Figura 3 estão apresentados os resultados da intenção de compra das geleias de rapadura e melado de cana-de-açúcar.

Figura 3. Intenção de compra das geleias de rapadura e melado de cana-de-açúcar.

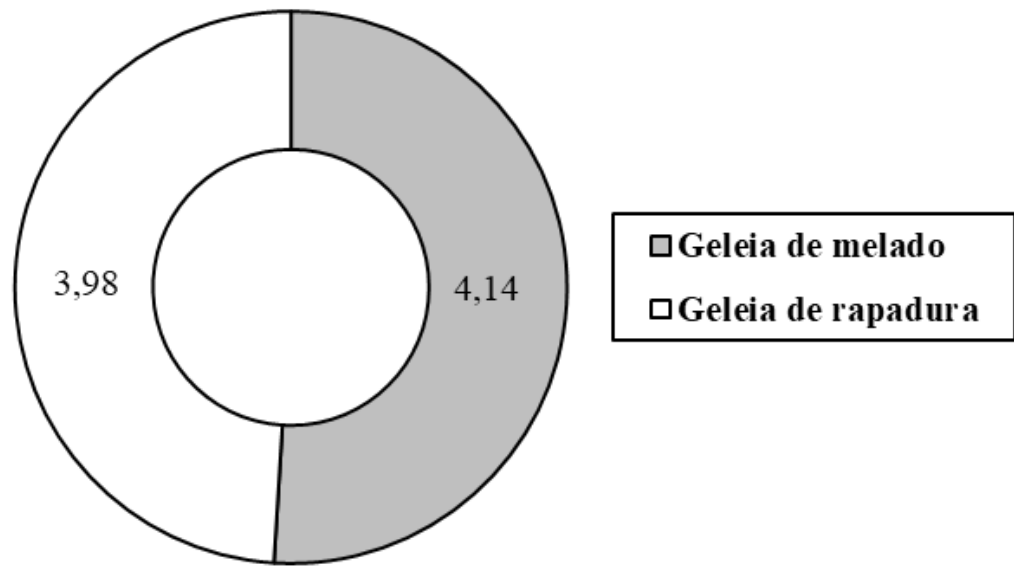

Fonte: Própria (2020).

$\mathrm{Na}$ intenção de compra das geleias, observou-se que a geleia de melado obteve nota média superior a geleia de rapadura, com 4,14 e 3,98, respectivamente. As notas obtidas correspondem aos termos hedônicos entre "talvez compraria/ talvez não compraria" e “certamente compraria", corroborando com os resultados apresentados na Figura 2.

Feitosa et al. (2017), ao aproveitarem a casca de banana na elaboração de quatro geleias com especiarias, obtiveram intenção de compra correspondente aos termos hedônicos "talvez 
compraria/ talvez não compraria" e "provavelmente compraria" para as geleias padrão, com cravo, canela e gengibre.

\section{Conclusões}

As formulações para a elaboração de geleias de rapadura e melado de cana-de-açúcar foram validadas, evidenciando produtos inovadores e com expressivo apelo regional. A geleia de rapadura apresentou características de pH pouco ácido e elevada concentração de sólidos, enquanto a geleia de melado demonstrou maior sensação de doçura.

Ambas as formulações foram bem aceitas sensorialmente, com índice de aceitabilidade acima de $70 \%$ em todos os atributos. A geleia de melado destacou-se com notas superiores nos atributos aparência, consistência, espalhabilidade e impressão global, provavelmente devido ser mais úmida. Porém, ainda são necessárias análises complementares para avaliar a estabilidade durante ao armazenamento.

\section{Referências}

AZEVÊDO, L. P. M.; NASCIMENTO, H. M. A.; MOREIRA, R. T.; PEREIRA, E. M. Elaboração e caracterização de doce de coco adicionado de diferentes concentrações de rapadura. Revista Verde de Agroecologia e Desenvolvimento Sustentável, v. 10. p.30-34, 2015. Disponível em: 〈https://doi.org/10.18378/rvads.v10i3.3585>.

BARRETO, P. P. A. F. A. P.; BETTANI, S. R.; BORGES, M. T. M. R.; BERNARDI, M. R. V. Avaliação físico-química e sensorial de diferentes melados. Revista de Agricultura, v. 90. p. 217-228, 2015. Disponível em: 〈https://doi.org/10.37856/bja.v90i3.66〉.

BARROS, S. L.; SILVA, W. P; FIGUEIRÊDO, R. M. F; ARAÚJO, T. J; SANTOS, N. C; GOMES, J. P. Efeito da adição de diferentes tipos de açúcar sobre a qualidade físico-química de geleias elaboradas com abacaxi e canela. Principia, v. 45. p. 150-157, 2019. Disponível em: <https://doi.org/10.18265/1517-03062015v1n45p150-157>.

BATISTA, E. M.; BARCElOS, S. C.; SILVA, E. F.; SÁ, D. M. A. T.; CAVALCANTE, A. B. D. Características físico-químicas e composição centesimal de rapaduras tradicionais. Higiene Alimentar, v. 3. p. 1314-1318, 2019. Disponível em: <http://www.higienista.com.br/wpcontent/uploads/Anais-Higienistas-2019_VERS\%C3\%83O-ATUALIZADA-FINAL.pdf>.

BRASIL. Agência Nacional de Vigilância Sanitária. Resolução - CNNPA no 12, de 1978. Normas Técnicas Especiais: padrões de identidade e qualidade para os alimentos (e bebidas). Diário Oficial [da] República Federativa do Brasil. São Paulo, 1978.

BRASIL. Agência Nacional de Vigilância Sanitária. Resolução RDC n 272, de 22 de setembro de 2005. Regulamento técnico para produtos de vegetais, produtos de frutas e cogumelos comestíveis. Diário Oficial [da] República Federativa do Brasil, Brasília, 2005.

CAETANO, P. K.; DAIUTO, É. R.; VIEITES, R. L. Caracterização físico-química e sensorial de geleia elaborada com polpa e suco de acerola. Brazilian Journal of Food Technology, 
Campinas, v. 15. p. 191-197, 2012. Disponível em: <https://doi.org/10.1590/S1981$\underline{67232012005000011>\text {. }}$

CASTRO, T. M. N.; ZAMBONI, P. V.; DOVADONI, S.; CUNHA NETO, A.; RODRIGUES, L. J. Parâmetros de qualidade de polpas de frutas congeladas. Revista do Instituto Adolfo Lutz, São Paulo, p. 426-436, 2015. Disponível em: <http://www.ial.sp.gov.br/resources/insituto-adolfolutz/publicacoes/rial/10/rial74_4_completa/artigos-separados/1677.pdf $>$.

CONAB. Companhia Nacional de Abastecimento. Acompanhamento da safra brasileira de cana-de-açúcar. Observatório agrícola. Brasília: Conab, 2019. ISSN 2318-7921.

DELGADO, L. C.; BORGES, G. N.; VAlENTINI, C. M. A.; FARIA, R. A. P. G. Aspectos culturais e ambientais no processo de produção de rapadura na comunidade de Bonsucesso em Várzea Grande-MT. Biodiversidade, v. 15, n. 2, p. 21-39, 2016. Disponível em: <http://periodicoscientificos.ufmt.br/ojs/index.php/biodiversidade/article/view/3958/2753 >.

DÍAZ, M. M. O.; QUIÑÓNEZ, L. V. C. R. Evaluation of the social-environmental impacts associated with the production of panela in Santander (Colombia). Corpoica Ciencia $\mathbf{y}$ Tecnología Agropecuaria, v. 18, n. 2, p. 379-396, 2017. Disponível em: <https://doi.org/10.21930/rcta.vol18_num2_art:637>.

DUTCOSKY, S. D. Análise sensorial de alimentos. $4^{\mathrm{a}}$ ed. Curitiba: Champagnat, 2013. 531p.

EMÍDIO, J. E. Hidrólise enzimática na fabricação de melado de cana-de-açúcar. 2016. 67f. Dissertação (Mestrado em Agroecologia e Desenvolvimento Rural) - Universidade Federal de São Carlos, Araras, 2016.

FEITOSA, B. F.; DIAS, A. L.; OLIVEIRA, E. N. A.; ROCHA, É. M. F. F. Aproveitamento da casca de banana na elaboração de geleia com especiarias. IN: II Congresso Internacional da Diversidade do Semiárido, Anais... Campina Grande, 2017.

GARCIA, L. G. C.; GUIMARÃES, W. F.; RODOVAlHO, E. C.; PERES, N. R. A. A.; BECKER, F. S.; DAMIANI, C. Geleia de buriti (Mauritia flexuosa): agregação de valor aos frutos do cerrado brasileiro. Brazilian Journal Of Food Technology, p. 1-5. 2017. Disponível em: 〈https://doi.org/10.1590/1981-6723.4316>.

GOMES, R. B.; SANTOS, M. B.; CARDOSO, R. L.; TAVARES, J. T. Q.; CUNHA, D. S. Elaboração e avaliação físico-químico e sensorial de geleia de maracujá com cenoura. Enciclopédia Biosfera, v. 9, p. 2765-2770, 2013. Disponível em: $<$ https://www.conhecer.org.br/enciclop/2013a/agrarias/ELABORACAO\%20E\%20AVALIAC AO.pdf $>$.

GUILHERME, P. R.; PESSATTO, C. C.; ZAIKA, W. R.; QUAST, E.; QUAST, L. B.; ORMENESE, R. C. S. C.; RAUPP, D. S. Desenvolvimento de geleia de tamarillo contendo polpa integral. Brazilian Journal of Food Technology, v. 1 p. 141-149, 2012. Disponível em: <http://dx.doi.org/10.1590/S1981-67232012005000007>.

GULARTE, M. A. Análise sensorial. Universitária da Universidade Federal de Pelotas, 2009. 
IAL. Instituto Adolfo Lutz. Métodos físico-químicos para análise de alimentos. $4^{\mathrm{a}}$ ed., $1^{\mathrm{a}} \mathrm{ed}$. Digital, São Paulo, 2008. 1020p.

JERONIMO, E. M. Produção de açúcar mascavo, rapadura e melado no âmbito da agricultura familiar e sua importância na alimentação humana. Ciência Alimentando o Brasil. São Paulo, p. 111-120, 2018. Disponível em: < $\underline{\text { https://agbbauru.org.br/publicacoes/Alimentando2ed/pdf/Alimentando2ed-07.pdf }>\text {. }}$

MAIA, J. D.; TRAVÁLIA, B. M; ANDRADE, T. A; SILVA, G. K. C.; ANDRADE, J.K. S.; JÚNIOR, A. M. O.; MOREIRA, J. J. S. Desenvolvimento, avaliação físico-química, microbiológica e sensorial de geleia de tamarindo. Revista Gestão, Inovação e Tecnologias, v. 4. p. 632-641, 2014.

OLIVEIRA, E. N. A.; FEITOSA, B. F.; SOUZA, R. L. A. Tecnologia e processamento de frutas: doces, geleias e compotas. 1 ed. Natal: Editora IFRN, 2018. 316p. ISBN: 978-8594137-48-7.

$<$ https://memoria.ifrn.edu.br/bitstream/handle/1044/1664/Tec.\%20e\%20Proc.\%20de\%20Frut as\%20-\%20E-Book.pdf? sequence $=1 \&$ isAllowed $=\mathrm{y}>$.

OLIVEIRA, E. N. A; SANTOS, D. C; ROCHA, A. P. T; GOMES, J. P.; FEITOSA, R. M.; FEITOSA, B. F. Composição nutricional de geleias de umbu-cajá durante estocagem em temperatura ambiente. Brazilian of Journal of Food Technology, v. 21, e2018033, 2018. Disponível em: 〈https://doi.org/10.1590/1981-6723.3318>.

OLIVEIRA, E. N. A; SANTOS, D. C; ROCHA, A. P. T; GOMES, J. P. Perfil microbiológico e sensorial de geleias convencionais de umbú-caja. Comunicata Scientiae, v. 6. p.250-254, 2015. Disponível em: 〈https://dialnet.unirioja.es/servlet/articulo?codigo=6294664>.

OLIVEIRA, M. M. T.; BRAGA, T. R.; PINHEIRO, G. K.; SILVA, L. R.; VIEIRA, C. B.; TORRES, L. B. V. Parâmetros físico-químicos, avaliação microbiológica e sensorial de geleias de laranja orgânica com adição de hortelã. Revista de la Facultad de Agronomía, v. 115. p. 29-34, 2016.

Disponível em: $<$ http://sedici.unlp.edu.ar/bitstream/handle/10915/54166/Documento_completo.pdfPDFA.pdf?sequence $=1 \&$ isAllowed $=\mathrm{y}>$.

OLIVEIRA, K. D. C.; SILVA, S. S; LOSS, R. A; GUEDES, S. F. Análise sensorial e físicoquímica de geleia de achachairu (Garcinia humillis (Vahl) C. D. Adam). Segurança Alimentar e Nutricional, v. 26. p. 1-10, 2019. Disponível em: <https://doi.org/10.20396/san.v26i0.8653566>.

OLIVEIRA NETO, J. O.; FEITOSA, B. F.; GERMANO, A. M. L. O.; FREITAS, P. V. C.; ROCHA, É. M. F. F.; OLIVEIRA, E. N. A. Geleias enriquecidas com farinha do resíduo agroindustrial de abacaxi: elaboração e caracterização. IN: II ENCONTRO NACIONAL DA AGROINDUSTRIA, Anais... Bananeiras, p. 901-905, 2016.

RADDATTZ, C.; ROSSATO, M. V.; PICCININ, Y. Apuração dos custos de produção e do resultado em uma agroindústria. IN: XXII CONGRESSO BRASILEIRO DE CUSTOS, Anais... Foz do Iguaçu, PR, Brasil, 2015. 
RYBKA, A. C. P; LIMA, A. S; CASTRO, C. D. P. C. Geleia de manga "Tommy Atkins" adicionada de fibras - Aceitação sensorial. IN: CONGRESSO BRASILEIRO DE CIÊNCIA E TECNOLOGIA DE ALIMENTOS, Anais... v. 26. p. 1-8, 2018.

SANTOS, F; BORÉM, A. Cana-de-açúcar: do plantio à colheita. Viçosa, MG: Universidade Federal de Viçosa, 2013. 257p. ISBN 978-85-914438-0-2.

SEBRAE. Produtos derivados da cana-de-açúcar, 2014. Disponível em: $<$ https://respostas.sebrae.com.br/produtos-derivados-da-cana-de-acucar/>. Acesso em: 28 jul. 2020.

SILVA, F. A. Z.; AZEVEDO, C. A. V. The assistat software version 7.7 and its use in the analysis of experimental data. African Journal of Agricultural Research, v. 11, n. 3, p. 37333740, 2016. Disponível em: 〈https://doi.org/10.5897/AJAR2016.11522〉.

SOARES, E. A. Avaliação físico-química e sensorial de caldo de cana-de-açúcar. 2017. 49f. Dissertação (Mestrado em Agroecologia e Desenvolvimento Rural) - Universidade Federal de São Carlos, Araras, 2017.

SOUZA, F. G.; BARBOSA, F. F.; RODRIGUES, F. M. Avaliação de geleia de tamarindo sem pectina e com pectina proveniente do albedo do maracujá amarelo. Journal of Bioenergy And Food Science, v. 3. p. 78-88, 2016. Disponível em: 〈https://doi.org/10.18067/jbfs.v3i2.52〉.

TACO. Tabela Brasileira de Composição de Alimentos. TBCA - 7.1, 2020. Disponível em: <http://www.tbca.net.br/index.html>. Acesso em: 28 jul. 2020.

TELES, A. C. M.; PINTO, E. G.; SANTOS, J. R.; OLIVEIRA, C. F. D.; SOARES, D. S. B. Desenvolvimento e caracterização físico-química de geleia comum e extra de graviola com pimenta. Revista de Agricultura Neotropical, v. 4. p. 72-77, 2017. Disponível em: <https://doi.org/10.32404/rean.v4i1.1341>.

VIEIRA, E. C. S.; SILVA, E. P.; AMORIM, C. C. M.; SOUSA, G. M.; BECKER, F. S.; DMIANI, C. Aceitabilidade e características físico-químicas de geleia mista de casca de abacaxi e polpa de pêssego. Científica, v. 45. p. 115-122, 2017. Disponível em: <http://dx.doi.org/10.15361/1984-5529.2017v45n2p115-122>.

VICENTINI-POLETTE, C. M. Caracterização físico-química e sensorial de melados comerciais de cana-de-açúcar. 2019. 58 f. Dissertação (Mestrado em Agroecologia e Desenvolvimento Rural) - Universidade Federal de São Carlos, 2019. 